\title{
EARLY LUNG CANCER DETECTION IN URANIUM MINERS WITH ABNORMAL
}

\section{SPUTUM CYTOLOGY}

\author{
Technical Progress Report
}

for period July 31, 1991 - July 31, 1992

Geno Saccomanno, Ph. D., M.D., Pathologist

Principal Investigator

St. Mary's Hospital \& Medical Center

Grand Junction

August, 1992

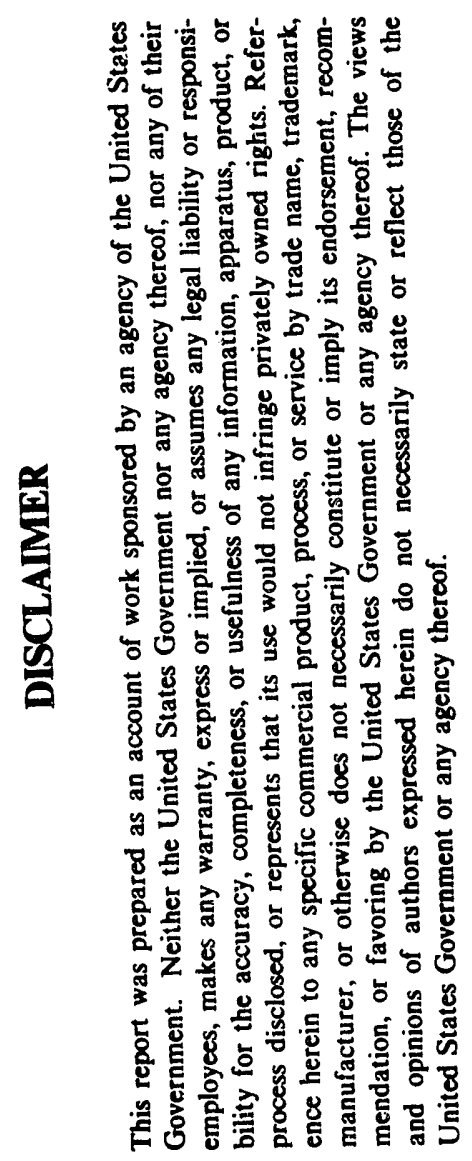

Prepared for

THE UNITED STATES DEPARTMENT OF ENERGY

AGREEMENT NO. DE-FG02-90ER60939 
DE-FG02-90ER60939

\begin{abstract}
This work supported by the United States Department of Energy, continues to add data on the health affects of cigarette smoking and radon exposure on uranium miners.

Since the last Technical Progress Report in July of 1991, 537 sputum cytology samples have been collected on the 300 uranium workers in the surveillance study.

To date there are 436 lung cancer cases in the Uranium Miner Tumor Registry with diagnostic slides from surgery and/or autopsy; an additional 40 cases have been diagnosed with sputum cytology only.

In March of 1991 the Geno Sacoomanno Uranium Workers Archive was established at St. Mary's Hospital and Medical Center as a depository for biological specimens and epidemiological data from the 17,700 uranium miners who have been a part of the study.
\end{abstract}


DE-FG02-90ER60939

The continuation of the research study began over 35 years ago by Dr. Geno Saccomanno and funded by the Department of Energy continues to add valuable data on the health effects of cigarette smoking and radon exposure.

The scope of these studies consists of the routine collection, processing and evaluation of sputum. Cytology specimens on uranium miners diagnosed with atypical pulmonary cells. This is done in an effort to identify cell changes consistent with early lung cancer in this high risk population. This study continues to accumulate epidemiological data, diagnostic microscopic slides and medical records on uranium miners who ultimately develop lung cancer.

Since the last report. 537 sputum samples have been evaluated on 300 miners in the ongoing surveillance study. Eleven new lung cancers were diagnosed from this group of patients in 1991 of which nine have been added to the tumor registry. At this time there are 436 tissue confirmed lung cancer cases with an additional 40 cases by sputum cytology alone.

The Geno Saccomanno Uranium Workers Archive was established as St. Mary's Hospital and Medical Center in March 1991. This dedicated room will act as a depository for microscopic slides, tissue sections and corresponding blocks on this group of individuals.

The computerized summary of the data base held in paper archives at St. Mary's Hospital and funded by the El Pomar Foundation is almost two thirds completed. The input of an estimated 200,000 records which include: patient demographics, smoking history, work histories, cytologic and histologic diagnosis and the clinical $x$-ray findings will constitute the largest study of its kind in the United States.

Tissue samples on surgical cases of primary bronchogenic cancer are harvested for molecular and genetic studies in a collaborative effort with the University of New Mexico Tumor Registry and the National Institute of Health (NIH). A total of eleven tumors and blood sample controls were collected in the past calendar year. These were from uranium miners and non miners who were 
diagnosed at St. Mary's Hospital.

Archival tissue (103 cuses miners and non miner controls) were sent to NIH for molecular studies involving the p53 suppressor gene and the ras oncogene which have been identified as a possible biologic link to lung cancer genesis.

Over 325 requests for documentation on smoking histories, radon exposure and confirmation of lung cancer diagnosis on uranium miners from our study have been received from the Justice Department in Washington D.C. This information is necessary to confirm eligibility for compensation under the Federally Approved Radon Exposure Compensation Act. It is estimated that our study alone has the necessary documentation on over $80 \%$ of all eligible underground uranium miners and mine workers. 

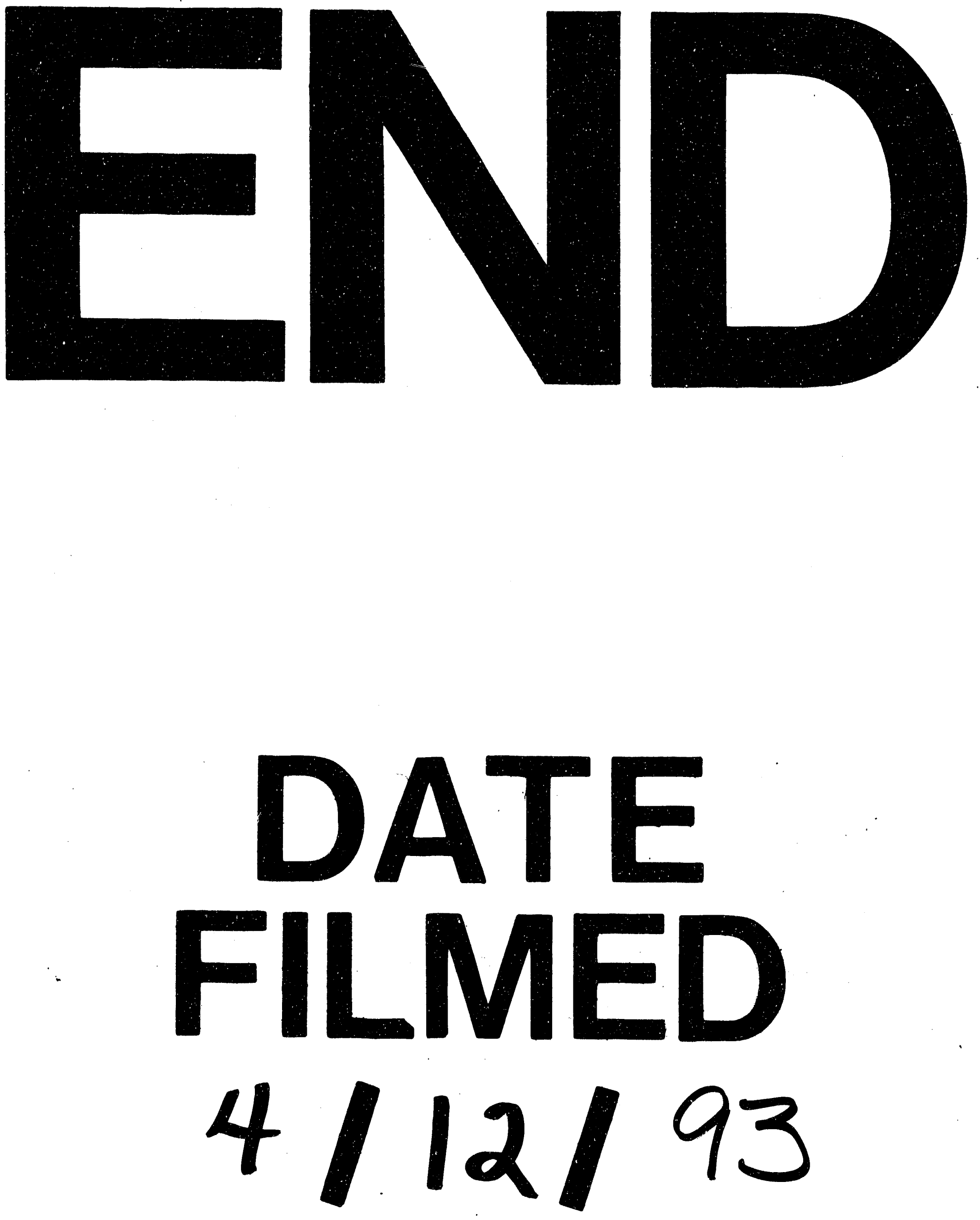

1 
